\title{
M-IDEALS AND THE BISHOP-PHELPS THEOREM
}

\section{INDUMATHI}

Abstract. We give new proofs for the known important approximative properties of M-ideals, using only the definition of an M-ideal and the Bishop-Phelps theorem. Unlike the known proofs, these proofs do not use the 3-ball intersection property of M-ideals.

Mathematics subject classification (2010): 46B20,41A50,41A65. functional.

Keywords and phrases: Proximinal, M-ideal, metric projection, M and L-summands, norm attaining

\section{REFERENCES}

[1] E. Behrends, M-Structure and the Banach-Stone theorem, Lecture Notes in Math. 736, Springer, Berlin-Heidelberg-New York, 1979.

[2] E. BEHRENDS AND P. HARMAND, Banach spaces which are proper M-ideals, Studia Math. 81 (1985), $159-169$.

[3] E. Bishop AND R. R. Phelps, The support functionals of a convex set, Convexity (Victor L. Klee, ed.), Proc. of symposia in Pure Math., Vol. 7, Amer. Math. Soc (1963), 27-35.

[4] H. FAKHOURY, Existence d'une projection continue de meilleuer approximation dans certains espaces de banach, J. Math. pures et appl. 53 (1974), 1-16.

[5] G. Godefroy And V. Indumathi, Norm-to-weak upper semi-continuity of the duality and Preduality mappings, Set-Valued analysis 10 (2002), 317-330.

[6] P. HARMAND, D. Werner AND W. Werner, M-ideals in Banach spaces and Banach algebras, Lecture Notes in Math. 1574, Springer, Berlin-Heidelberg-New York, 1993.

[7] R. B. Holmes, B. SCRANTON, AND J. WARD, Approximation from the space of compact operators and other M-ideals, Duke Math.J. 42 (1975), 259-269.

[8] V. Indumathi and S. Lalithambigai, A new proof of proximinality for M-ideals, Proc. Amer. Math. Soc. 135, 4 (2007), 1159-1162.

[9] Asvald Lima, On M-ideals and best approximation, Indiana Univ. Math. J. 31 (1982), 27-36.

[10] Robert E. Megginson, An introduction to Banach space theory, Springer, 1988.

[11] David Yost, Best approximation and intersection of balls in Banach spaces, Bull. Austral. Math. Soc. 20 (1979), 285-300. 